\title{
Chosen single nucleotide polymorphisms (SNPs) of enamel formation genes and dental caries in a population of Polish children
}

\author{
Karolina Gerreth ${ }^{1, A-D, F}$, Katarzyna Zaorska ${ }^{2, A-D, F}$, Maciej Zabel2, C, E, F, Maria Borysewicz-Lewicka ${ }^{1, A, C, E, F}$, Michał Nowicki2, A, C, E, F \\ 1 Department of Pediatric Dentistry, Poznan University of Medical Sciences, Poland \\ ${ }^{2}$ Department of Histology and Embryology, Poznan University of Medical Sciences, Poland \\ A - research concept and design; $\mathrm{B}$ - collection and/or assembly of data; $\mathrm{C}$ - data analysis and interpretation; \\ $D$ - writing the article; $E$ - critical revision of the article; $F$ - final approval of article
}

Address for correspondence

Karolina Gerreth

E-mail: karolinagerreth@poczta.onet.pl

\section{Funding sources}

The research was supported by grant from Poznan University of Medical Sciences (502-01-02207319-08716).

\section{Conflict of interest}

None declared

\section{Acknowledgements}

The authors thank the children who participated in the study for agreement and cooperation, their parents for the informed consent and the staff of the day nurseries for help in carrying out the patients' examination.

Received on November 21, 2015

Revised on March 3, 2016

Accepted on May 5, 2016

\section{Abstract}

Background. It is increasingly emphasized that the influence of a host's factors in the etiology of dental caries are of most interest, particularly those concerned with genetic aspect.

Objectives. The aim of the study was to analyze the genotype and allele frequencies of single nucleotide polymorphisms (SNPs) in AMELX, AMBN, TUFT1, TFIP11, MMP2O and KLK4 genes and to prove their association with dental caries occurrence in a population of Polish children.

Material and methods. The study was performed in 96 children (48 individuals with caries - "cases" and 48 free of this disease - "controls"), aged 20-42 months, chosen out of 262 individuals who had dental examination performed and attended 4 day nurseries located in Poznan (Poland). From both groups oral swab was collected for molecular evaluation. Eleven selected SNPs markers were genotyped by Sanger sequencing. Genotype and allele frequencies were calculated and a standard $x^{2}$ analysis was used to test for deviation from Hardy-Weinberg equilibrium. The association of genetic variations with caries susceptibility or resistance was assessed by the Fisher's exact test and $p \leq 0.05$ was considered statistically significant.

Results. Five markers were significantly associated with caries incidence in children in the study: rs 17878486 in AMELX ( $p<0.0001)$, rs34538475 in AMBN ( $p<0.0001)$, rs2337360 in TUFT1 ( $p<0.0001)$, and rs2235091 ( $p=0.0085)$ and rs $198969(p=0.0069)$ in KLK4. Genotype and allele frequencies indicated both risk and protective variants for these markers.

Conclusions. Single nucleotide polymorphisms in AMELX, AMBN, TUFT1, KLK4 genes may be considered as a risk factor for dental caries occurrence in Polish children.

Key words: children, single nucleotide polymorphism, dental caries, enamel formation genes

DOI

$10.17219 /$ acem/63024

Copyright

Copyright by Author(s)

This is an article distributed under the terms of the

Creative Commons Attribution Non-Commercial License

(http://creativecommons.org/licenses/by-nc-nd/4.0/) 
Dental caries is a complex and multifactorial chronic disease that develops by the interaction of variables over time, and currently remains the most common disorder of childhood., ${ }^{1,2}$ The pathology develops in abnormal conditions of environmental stability on the tooth surface, i.e. when there is imbalance between the process of demineralization and remineralization of the enamel. ${ }^{2}$ At present, the disease remains a serious health and social problem.

It is increasingly emphasized that the influence of a host's factors in the etiology of dental caries are of most interest, particularly those concerned with genetic aspect. Literature data describes possible association between the genes responsible for production of different enamel proteins and dental caries occurrence. ${ }^{1,4-13}$

Mature tooth enamel consists almost completely of inorganic material (above 90\%). However, during the development it is composed of organic matrix, which is mostly replaced by mineral compounds.

Numerous chemical and physiological processes, such as protein secretion, assembly, folding and degradation, mineral growth as well as gene expression are responsible for the production of the tooth enamel. ${ }^{14}$ The extracellular proteins situated between dentin and ameloblasts control the initiation, organization and orientation of crystals in the enamel. ${ }^{14}$

Ameloblasts, which are cells producing the enamel, are of epithelial origin and their activity is strictly dependent on the differentiation of odontoblasts, i.e. dentin-making cells of mesenchymal origin. ${ }^{14}$ Ameloblasts during the secretory stage produce and secrete proteins into the matrix of the enamel, which are exchanged by phosphate and calcium at the maturation stage. ${ }^{15}$ The most significant secretory proteins may be divided into amelogenin and nonamelogenin proteins. ${ }^{15}$ Amelogenin constitutes more than $90 \%$ of the extracellular matrix protein content and is suggested to control the oriented growth and organization of enamel crystals. ${ }^{14,16}$ This protein is expressed from genes on the $\mathrm{Y}$ and $\mathrm{X}$ chromosomes, however, approx. $90 \%$ of all RNA transcripts are from the chromosome X. ${ }^{17}$ Nonamelogenins include ameloblastin, enamelin and tuftelin. Ameloblastin is functioning as cell adhesion protein and is responsible for maintaining rod integrity and controlling cell differentiation. ${ }^{14}$ Enamelin is involved, in cooperation with amelogenin, in controlling elongated growth and mineral nucleation ${ }^{14}$, whereas tuftelin is proposed to be a potential nucleator of enamel crystallites. ${ }^{18}$ It is interesting that currently 2 other enamel matrix proteins were discovered, odontogenic ameloblast-associated (ODAM/APIN) and amelotin. ${ }^{15}$

During the maturation stage the matrix is quickly degraded since at that time apatite crystals grow primarily in thickness and width, and finally it is removed from the extracellular space and the mineralization is completed. ${ }^{15}$

Ameloblasts secrete also proteinases, such as matrix metalloproteinase-20 and kallikrein-related peptidase-4, which function during different stages of amelogenesis and cause amelogenin and other enamel proteins degradation. ${ }^{14}$
The aim of the study was to analyze the genotype and allele frequencies of single nucleotide polymorphisms (SNPs) in $A M E L X$ (amelogenin, $\mathrm{X}$ isoform), $A M B N$ (ameloblastin), TUFT1 (tuftelin), TFIP11 (tuftelin-interacting protein 11), MMP20 (matrix metalloproteinase-20) and KLK4 (kallikrein-related peptidase-4) genes and to prove their association with dental caries occurrence in a population of Polish children.

\section{Material and methods}

\section{Determination of caries phenotype}

Study subjects were recruited from 4 day nurseries which constitute 1 institution, located in the city of Poznan, in the Wielkopolska Province, Poland. Caries was diagnosed by visual examination, using a probe and a dental mirror to confirm such a change. It was carried out from April to June 2014 by 1 trained and calibrated dentist, a specialist in pediatric dentistry after calibration by an experienced specialist. Dental evaluation concerned the occurrence of teeth with carious cavities (dt) as well as teeth with initial (incipient) caries lesions (noncavitated, white spot) $\left(\mathrm{d}_{\mathrm{i}}\right)$. The intra-examiner agreement was evaluated by another dental examination in 10 children after 2 weeks, with a $\mathrm{k}$ of 1.00 . In total, 262 children who attended the day nurseries and whose parents gave written informed consent were examined. Oral swabs for DNA extraction were collected during the examination. In cases when the quality of the biological material for molecular analysis was poor, the sample was taken once again on subsequent visits, up to 2 or 3 times. In 48 subjects dental caries was diagnosed $\left(\mathrm{dt}+\mathrm{d}_{\mathrm{i}} \geq 1\right)$, and they were classified as the study group ("cases"). In those children 1 child had, apart from carious lesions, 1 filled tooth. From the remaining 214 subjects, who were free of the disease $\left(d t+d_{i}=0\right)$, and had no filled teeth, the control group of 48 counterparts was selected ("controls"). The age of all individuals was 20-42 months and the study and control subjects were matched by gender, age and the number of erupted teeth. The specimens from children of other than Caucasian ethnic group were excluded from this study.

\section{Sample collection and genotyping}

Oral swabs were provided to each subject in sterile packs. The inside of the mouth was rubbed at least 10 times from each side of both cheeks and then the swab was placed inside the $1.5 \mathrm{~mL}$ Eppendorf tube and placed at $+4^{\circ} \mathrm{C}$ in a portable fridge. Genomic DNA was extracted from buccal cells using the column system from EXTRACTME DNA Swab \& Semen Kit from Blirt S.A., according to the manufacturer's protocol. DNA extraction was carried out the same day when the oral examina- 
tion was done and the DNA samples were frozen in $-20^{\circ} \mathrm{C}$ until further analyses.

We performed genotyping of 11 single nucleotide polymorphisms (SNPs) in 6 enamel formation genes, as followed: rs17878486 in AMELX, rs34538475 and rs4694075 in $A M B N$, rs3790506, rs4970957 and rs2337360 in TUFT1, rs134136 and rs5997096 in TFIP11, rs1784418 in $M M P 20$, rs2235091 and rs198969 in KLK4. All genetic markers were genotyped by the real-time polymerase chain reaction (PCR) using the TaqMan method (Life Technologies), in which 2 probes - each for 1 allele in a 2-allele system - discriminate between 2 polymorphic variants. SNPs selected for the study are listed in Table 1.

The quantitative real-time PCRs were performed on the 96-well optical reaction plates using the $7900 \mathrm{HT}$ real-time PCR system (Applied Biosystems), following the manufacturer's protocol. For each sample reactions were carried out in a $25 \mu \mathrm{L}$ total reaction volume, using $12.5 \mu \mathrm{L}$ of TaqMan genotyping master mix, $1.25 \mu \mathrm{L}$ of $\times 20$ probe and $11.25 \mu \mathrm{L}$ of genomic DNA. DNA samples were adjusted to $10 \mathrm{ng}$ per $11.25 \mu \mathrm{L}$ by diluting the sample with appropriate amount of nuclease-free water (Ambion). The TaqMan probes were shipped in $\times 40$ concentration and were diluted to $\times 20$ working stocks with $\times 1 \mathrm{TE}$ buffer, prior to the analyses. The cycling conditions were as follows: an initial denaturation at $95^{\circ} \mathrm{C}$ for $10 \mathrm{~min}$ followed by 40 cycles of denaturation at $92^{\circ} \mathrm{C}$ for $15 \mathrm{~s}$ and annealing/extension at $60^{\circ} \mathrm{C}$ for $1 \mathrm{~min}$. Allelic discrimination data was captured with ABI SDS software (Life Technologies).

Table 1. Single nucleotide polymorphisms analyzed for candidate genes in the study

\begin{tabular}{|c|c|c|c|c|}
\hline No. & Gene & Genetic marker & $\begin{array}{l}\text { Chromosome } \\
\text { (Chr.) position }\end{array}$ & $\begin{array}{l}\text { MAF (minor } \\
\text { allele } \\
\text { frequency) }\end{array}$ \\
\hline 1. & AMELX & rs17878486 & Chr.X:11313948 & 0.11 \\
\hline 2. & & rs34538475 & Chr.4:71471176 & 0.19 \\
\hline 3. & & rs4694075 & Chr.4:71466914 & 0.48 \\
\hline 4. & & rs3790506 & Chr.1:151538366 & 0.25 \\
\hline 5. & TUFT1 & rs4970957 & Chr.1:151517388 & 0.25 \\
\hline 6. & & rs2337360 & Chr.1:151514603 & 0.25 \\
\hline 7. & & rs134136 & Chr.22:26899474 & 0.34 \\
\hline 8. & & rs5997096 & Chr.22:26895957 & 0.47 \\
\hline 9. & MMP20 & rs1784418 & Chr.11:102484396 & 0.41 \\
\hline 10. & & rs2235091 & Chr.19:51410471 & 0.34 \\
\hline 11. & & rs198969 & Chr.19:50910546 & 0.43 \\
\hline
\end{tabular}

\section{Statistical analysis}

Genotype and allele frequencies were calculated and a standard $X^{2}$ analysis was used to test for deviation from Hardy-Weinberg equilibrium. The association of genetic variations with caries susceptibility or resistance was assessed by the Fisher's exact test and $\mathrm{p} \leq 0.05$ was considered statistically significant. Odds ratio (OR) values were calculated for the minor allele and for the heterozygote and minor homozygote. All calculations were performed so as to put the group expected to have higher number of observations in the first column, so the OR results could be interpretable directly. ${ }^{19}$ In addition, we used HaploView 4.2 software to test pairwise association between studied single nucleotide variations, using Gabriel et al. algorithm and shown as $\mathrm{R}^{2}$ value. ${ }^{20}$ We defined SNP pairs to be in "strong LD" (LD-linkage disequilibrium) when the lower bound of $\mathrm{R}^{2}$ (coefficient of determination) value was above 0.7 (70\%). ${ }^{20}$

For a statistical analysis relating to the differences between study and control group, as to age the student's t-test was used, as to gender the Pearson's $X^{2}$, whereas as to number of erupted teeth Mann-Whitney $U$ test. The statistical analysis was done with the use of STATISTICA v. 8.0. The assumed level of statistical significance was $\mathrm{p}<0.05$.

\section{Ethical Committee approval}

The study was approved by the Ethics Committee of Poznan University of Medical Sciences.

\section{Results}

\section{Homogeneity of the study and control group}

In the study group there were 25 females (52.08\%) and 23 males $(47.92 \%)$ when in the controls respectively, 24 (50.00\%) and 24 (50.00\%), and the differences were not statistically significant $(\mathrm{p}=0.838)$.

The statistically insignificant differences $(p=0.532)$ were observed in the children's age since in the study and control group it amounted from 20 to 42 months, but the mean \pm SD (standard deviation) was respectively, $30.58 \pm 5.91$ and $29.85 \pm 5.48$. In the "cases", females were aged $20-40$ months (30.88 \pm 5.72$)$, while males 20-42 months (30.26 \pm 6.22$)$, whereas in "controls" girls were $20-38$ months old $(28.33 \pm 5.40)$ and boys were 20-42 months old ( $31.38 \pm 5.23)$.

Cases had from 11 to 20 erupted teeth $($ mean $\pm \mathrm{SD}=18.56 \pm 2.29)$, while controls had $12-20$ erupted teeth (mean $\pm \mathrm{SD}=18.14 \pm 2,16$ ), and the differences were not statistically significant $(p=0.265)$. 
Table 2. Summary of allele and genotype frequency related to caries experience in 11 studied SNPs

\begin{tabular}{|c|c|c|c|c|c|c|c|c|c|}
\hline \multirow{2}{*}{ Genetic marker } & \multirow{2}{*}{\multicolumn{3}{|c|}{ Genotypes }} & \multicolumn{2}{|c|}{ Cases vs control } & \multirow{2}{*}{\multicolumn{2}{|c|}{ Alleles }} & \multicolumn{2}{|c|}{ Cases vs control } \\
\hline & & & & OR [Cl 95\%] & p-value & & & OR [Cl 95\%] & $p$-value \\
\hline \multirow{3}{*}{$\begin{array}{l}\text { rs17878486 } \\
\text { AMELX } \\
\text { Caries } n=48 \\
\text { Control } n=48\end{array}$} & $\mathrm{CC}$ & $\mathrm{CT}$ & TT & & & $\mathrm{C}$ & $\mathrm{T}$ & & \\
\hline & $8(16.7 \%)$ & $10(20.8 \%)$ & $30(62.5 \%)$ & CC: 0.11 [0.04-0.2] & $<0.0001^{* * *}$ & $26(27.1 \%)$ & 70 (72.9\%) & T: 10.2 [5.2-20] & $<0.0001^{* * *}$ \\
\hline & 31 (64.6\%) & $14(29.2 \%)$ & $3(6.2 \%)$ & TT: 25 [6.8-92.4] & $<0.0001^{* * *}$ & $76(79.2 \%)$ & $20(20.8 \%)$ & & \\
\hline \multirow{4}{*}{$\begin{array}{l}\text { rs34538475 } \\
\text { AMBN } \\
\text { Caries } n=48 \\
\text { Control } n=48\end{array}$} & GG & GT & TT & & & G & $\mathrm{T}$ & & \\
\hline & $27(56.3 \%)$ & $17(35.4 \%)$ & $4(8.3 \%)$ & GG: 5.6 [2.2-14] & $0.0003^{* * *}$ & $71(74.0 \%)$ & $25(26.0 \%)$ & G: 7 [3.7-13] & $<0.0001^{* * *}$ \\
\hline & & & & control vs c & ases & & & control v & cases \\
\hline & $9(18.8 \%)$ & $10(20.8 \%)$ & $29(60.4 \%)$ & TT: 17 [5.2-54.4] & $<0.0001^{* * *}$ & $28(29.2 \%)$ & $68(70.8 \%)$ & T: 6.9 [3.7-13] & $<0.0001^{* * *}$ \\
\hline \multirow{2}{*}{$\begin{array}{l}\text { rs } 4694075 \\
\text { AMBN } \\
\text { Caries } n=48 \\
\text { Control } n=48\end{array}$} & $16(33.3 \%)$ & $20(41.7 \%)$ & $12(25.0 \%)$ & CC: $1.5[0.6-3.6]$ & 0,3703 & $52(54.2 \%)$ & $44(45.8 \%)$ & C: 1,5 [0.9-2.7] & 0.1496 \\
\hline & $12(25.0 \%)$ & $18(37.5 \%)$ & $18(37.5 \%)$ & CT: $1.2[0.5-2.7]$ & 0.6765 & $42(43.8 \%)$ & $54(56.2 \%)$ & $\mathrm{T}: 0.7$ [0.4-1.2] & 0.1496 \\
\hline \multirow{3}{*}{$\begin{array}{l}\text { rs3790506 } \\
\text { TUFT1 } \\
\text { Caries } n=48 \\
\text { Control } n=48\end{array}$} & $\mathrm{AA}$ & AG & GG & & & $A$ & G & & \\
\hline & $2(4.2 \%)$ & $18(37.5 \%)$ & 28 (58.3\%) & AG: 0.8 [0.4-1.9] & 0.6765 & 22 (22.9\%) & 74 (77.1\%) & G: 1.5 [0.8-2.9] & 0.1953 \\
\hline & $5(10.4 \%)$ & $20(41.7 \%)$ & $23(47.9 \%)$ & GG: $1.5[0.7-3.4]$ & 0.3074 & $30(31.2 \%)$ & $66(68.8 \%)$ & & \\
\hline \multirow{3}{*}{$\begin{array}{l}\text { rs4970957 } \\
\text { TUFT1 } \\
\text { Caries } n=48 \\
\text { Control } n=48\end{array}$} & AA & AG & GG & & & $A$ & G & & \\
\hline & $18(37.5 \%)$ & $29(60.4 \%)$ & $1(2.1 \%)$ & AG: 2.3 [1-5.3] & $0.0428^{*}$ & $65(67.7 \%)$ & 31 (32.3\%) & G: 1.5 [0.8-2.9] & 0.2004 \\
\hline & 27 (56.2\%) & 19 (39.6\%) & $2(4.2 \%)$ & GG: 0.5 [0.04-5.6] & 0.5651 & 73 (76.0\%) & $23(24.0 \%)$ & & \\
\hline \multirow{2}{*}{$\begin{array}{l}\text { rs } 2337360 \\
\text { TUFT1 } \\
\text { Caries } n=48 \\
\text { Control } n=48\end{array}$} & $36(75.0 \%)$ & 11 (22.9\%) & $1(2.1 \%)$ & AG: 0.06 [0.02-0.16] & $<0.0001^{* * *}$ & $83(86.5 \%)$ & $13(13.5 \%)$ & A: $4.6[0.1-0.4]$ & $<0.0001^{* * *}$ \\
\hline & $8(16.7 \%)$ & $40(83.3 \%)$ & $0(0.0 \%)$ & $\mathrm{AA}: 15$ [0.1-77.1] & $<0.0001^{* * *}$ & $56(58.3 \%)$ & $40(41.7 \%)$ & & \\
\hline \multirow{3}{*}{$\begin{array}{l}\text { rs134136 } \\
\text { TFIP11 } \\
\text { Caries } n=48 \\
\text { Control } n=48\end{array}$} & $\mathrm{CC}$ & $\mathrm{CT}$ & TT & & & C & $\mathrm{T}$ & & \\
\hline & 15 (31.2\%) & $25(52.1 \%)$ & $8(16.7 \%)$ & CT: $1.2[0.5-2.6]$ & 0.6832 & $55(57.3 \%)$ & $41(42.7 \%)$ & $\mathrm{T}: 1.2[0.7-2.1]$ & 0.5568 \\
\hline & $18(37.5 \%)$ & $23(47.9 \%)$ & $7(14.6 \%)$ & TT: 1.2 [0.5-2.6] & 0.7788 & $59(61.5 \%)$ & $37(38.5 \%)$ & & \\
\hline \multirow{3}{*}{$\begin{array}{l}\text { rs5997096 } \\
\text { TFIP11 } \\
\text { Caries } n=48 \\
\text { Control } n=48\end{array}$} & $\mathrm{CC}$ & $\mathrm{CT}$ & TT & & & $\mathrm{C}$ & $\mathrm{T}$ & & \\
\hline & $36(75.0 \%)$ & $12(25.0 \%)$ & $0(0.0 \%)$ & CT: 1.3 [0.5-3.3] & 0.6276 & $84(87.5 \%)$ & $12(12.5 \%)$ & $\mathrm{T}: 1.2[0.5-3]$ & 0.6508 \\
\hline & $38(79.2 \%)$ & $10(20.8 \%)$ & $0(0.0 \%)$ & & & $86(89.6 \%)$ & $10(10.4 \%)$ & & \\
\hline \multirow{3}{*}{$\begin{array}{l}\text { rs } 1784418 \\
\text { MMP20 } \\
\text { Caries } n=48 \\
\text { Control } n=48\end{array}$} & $\mathrm{CC}$ & $\mathrm{CT}$ & $\mathrm{TT}$ & & & $\mathrm{C}$ & $\mathrm{T}$ & & \\
\hline & $20(41.7 \%)$ & $23(47.9 \%)$ & $5(10.4 \%)$ & CT: 0.8 [0.3-1.7] & 0.5405 & $63(65.6 \%)$ & 33 (34.4\%) & T: 0.9 [0.5-1.6] & 0.6519 \\
\hline & $17(35.4 \%)$ & $26(54.2 \%)$ & $5(10.4 \%)$ & TT: 1 [0.3-3.7] & 1 & $60(62.5 \%)$ & $36(37.5 \%)$ & & \\
\hline \multirow{3}{*}{$\begin{array}{l}\text { rs2235091 } \\
\text { KLK4 } \\
\text { Caries } n=48 \\
\text { Control } n=48\end{array}$} & GG & GA & AA & & & G & A & & \\
\hline & $10(20.8 \%)$ & $18(37.5 \%)$ & $20(41.7 \%)$ & $\mathrm{GA}: 0.9[0.4-2.1]$ & 0.8339 & $38(39.6 \%)$ & $58(60.4 \%)$ & G: 2.3 [1.2-4.4] & $0.0085^{* *}$ \\
\hline & $1(2.1 \%)$ & 19 (39.6\%) & $28(58.3 \%)$ & GG: 12.4 [1.5-101] & $0.0189^{*}$ & $21(21.9 \%)$ & 75 (78.1\%) & & \\
\hline \multirow{3}{*}{$\begin{array}{l}\text { rs198969 } \\
\text { KLK4 } \\
\text { Caries } n=48 \\
\text { Control } n=48\end{array}$} & $\mathrm{CC}$ & CG & GG & & & $C$ & $\mathrm{G}$ & & \\
\hline & $14(29.2 \%)$ & $23(47.9 \%)$ & $11(22.9 \%)$ & CG: 0.9 [0.4-2] & 0.8382 & $51(53.1 \%)$ & 45 (46.9\%) & G: 2.4 [1.3-4.3] & $0.0049^{* *}$ \\
\hline & $23(47.9 \%)$ & $24(50.0 \%)$ & $1(2.1 \%)$ & GG: 14 [1.7-113.2] & $0.0135^{*}$ & $70(72.9 \%)$ & $26(27.1 \%)$ & & \\
\hline
\end{tabular}

${ }^{*} \mathrm{p} \leq 0.05 ;{ }^{* *} \mathrm{p} \leq 0.01 ;{ }^{* * *} \mathrm{p} \leq 0.001 ; \mathrm{OR}$ - odds ratio; $\mathrm{Cl}$ - confidence interval; A - adenine; $\mathrm{G}$ - guanine; C - cytosine; $\mathrm{T}$ - thymine. 


\section{SNPs and caries prevalence}

All genotypes were in Hardy-Weinberg equilibrium. Table 2 summarizes the results of genotype and allele frequency comparisons calculated for all 11 studied SNPs. We found that the differences in genotype and allele prevalence were statistically significant in $6 \mathrm{SNPs}$, indicating possible correlation of these marker with caries in children. For rs17878486 in AMELX gene there was higher incidence of the minor TT homozygote in caries experienced children in comparison with caries free individuals $(\mathrm{OR}=25, \mathrm{p}<0.0001)$. It was confirmed by the allele frequency analysis, as the prevalence of the alternative $\mathrm{T}$ allele was significantly more common in group with caries in comparison with the control group $(\mathrm{OR}=10.2$, $\mathrm{p}<0.0001)$. Those results indicate the $\mathrm{T}$ allele and TT genotype as a putative strong risk variants for caries experience in the study group.

The distribution for genotypes and alleles for $A M B N$ gene also revealed significant differences for 1 of the 2 studied SNPs. For rs34538475 there was higher prevalence of the minor TT homozygote and the minor $\mathrm{T}$ allele seen in controls in comparison to children with caries $(\mathrm{p}<0.0001$ for both calculations), which strongly indicates the $\mathrm{T}$ allele as a protective against caries variant in our study group. In the other studied SNP for $A M B N$ gene, rs4694075, genotype and allele frequencies did not differ significantly between caries and caries-free children.

In rs2337360 for TUFT1 gene there was also statistically significant frequency of the AG heterozygote and the minor $\mathrm{G}$ allele ( $\mathrm{p}<0.0001$ for both calculations) between the groups. We did not observe differences in genotype and allele frequencies in the other 2 SNPs for TUFT1 gene between caries and control children. Although, in rs4970957 there was a significant overrepresentation of the AG genotype in children with caries $(\mathrm{p}=0.0428)$, distribution of both homozygotes and alleles did not differ between caries and caries-free participants.

No significant association with caries phenotype was found in SNPs for TFIP11 and MMP20 genes. On the other hand, there were significant associations in both rs2235091 and rs198969 for KLK4 gene with caries occurrence. In rs198969, we observed significantly higher incidence of the major GG homozygote $(\mathrm{p}=0.0135)$ and the major $\mathrm{G}$ allele $(\mathrm{p}=0.0049)$ in children with caries than in controls. There was also a significantly different distribution of alleles $(p=0.0085)$ in rs2235091, however, the frequency of genotypes did not differ statistically between the groups.

\section{Allelic association analysis}

We conducted association test for each candidate gene (it was possible only when 2 or more SNPs for single gene were analyzed, i.e. for AMBN, TUFT1, TFIP11 and KLK4 genes) and for all markers, simultaneously. The analysis did not reveal presence of any haplotype block or significant association for studied markers. Interestingly, linkage disequilibrium, shown as $\mathrm{R}^{2}$ values was different between caries-free and caries experienced children (data not shown). There was stronger association between rs4694075 and rs34538475 for $A M B N$ gene in caries children $\left(R^{2}=19\right)$ than in controls $\left(R^{2}=1\right)$. The latter was significantly associated with caries, however no specific haplotype was revealed. We also observed weak association $\left(R^{2}=18\right)$ between rs5997096 and rs134136 for TFIP11 gene.

\section{Discussion}

Although there are several studies that strongly suggest a role for enamel formation genes in caries susceptibility, there are still some discrepancies in the results, mainly in relation to age, sex and ethnicity of the individuals studied. ${ }^{1,4-12}$ The present study is limited to Polish Caucasian children and, to the best of our knowledge, our study is the first one concerning the genetic aspect of dental caries to be performed on such a homogenous population in Poland. It is well established that multiple environmental as well as genetic factors contribute to caries. In this report, we investigated the role of single nucleotide polymorphisms in several genes related to enamel formation and development to evaluate their possible association with susceptibility to caries. All markers were chosen on the basis of previous reports concerning the association between genetic variants and caries phenotype in children. Studied SNPs were located in intronic regions of candidate genes, however, they could influence mRNA expression process and alter functional activities of encoded genes.

In fact, 4 of 11 markers were overrepresented in genotype and allele transmissions to caries-experienced or caries-free individuals, indicating the markers to be associated with caries. We found significant association between the minor T allele and TT homozygote in polymorphism rs17878486 for $A M E L X$ and caries experience. There was 25 -fold higher prevalence of the TT genotype and over 10-fold higher prevalence of the $\mathrm{T}$ allele in caries children than in caries-free children $(\mathrm{p}<0.0001$ for both calculations). Patir et al. observed an overrepresentation of the CC genotype in caries individuals (Turkish population), which is in contradiction with our results, where the major CC genotype turned out to be protective against caries occurrence. ${ }^{4}$ On the other hand, Abbasoğlu et al. found no association between the same AMELX polymorphism and caries susceptibility in Turkish children. ${ }^{5}$ There were also no associations between amelogenin genetic variants and dental caries experience in other studies performed on Polish, French, Caucasian, and Japanese populations..$^{6-8,12}$ However, studied SNPs for $A M E L X$ gene and the age of children were different 
from those chosen for our study, also the studied populations were heterogeneous regarding demographic origins and cultural diversity.

Another major enamel protein, ameloblastin, is in synergy with amelogenin during the process of enamel development, but, in contrary to the latter, does not exhibit diversity in gene structure or expression level in reference to gender. ${ }^{21}$ Abbasoğlu et al., Deeley et al. and Slayton et al. did not find association between $A M B N$ genetic variants and caries experience in Turkish, Guatemalan-Mayan and mixed populations, respectively, although Slayton et al. noticed that out of the children who participated in the study, Caucasian children had the greatest severity of the disease. ${ }^{5,7,11}$ On the other hand, Patir et al. observed an overrepresentation of the minor T allele in rs34538475 in caries experienced individuals in comparison to controls, regardless of the stage of the disease. ${ }^{4}$ In our study, however, we observed an opposite association, as both the minor T allele $(\mathrm{p}<0.0001)$ and the minor TT homozygote $(\mathrm{p}<0.0001)$ were overrepresented in controls in comparison to cases with caries, which supported the $\mathrm{T}$ allele as a protective variant. There were no differences in allele and genotype frequency between caries experienced and caries-free children in rs4694075 for $A M B N$ gene in our study. On the contrary, Schimizu et al. noticed an association between the major $\mathrm{C}$ allele and caries cases with higher dmft scores, however, the calculation was carried out for the caries group only and not for cases and controls. $^{10}$

In 1 of 3 variants studied for TUFT1 gene, i.e. rs2337360, we found a strong association between the overrepresented wild A allele and AA genotype ( $\mathrm{p}<0.0001$ for both calculations) and caries incidence, which supports this SNP as a risk variant. Interestingly, Deeley et al. noticed significant association between this marker and individuals with different dmft scores, but not when caries-free children were included in the comparisons. ${ }^{11}$ Several studies showed an association between other 2 markers (rs3790506 and rs4970957) for TUFT1 gene and caries experience, while in our study there were no differences in genotype and allele distribution or the results were inconclusive. ${ }^{4,5,10}$ It is worth mentioning that in most of the studies concerning genetic variation of tuftelin and caries, an association could only be detected when the interaction with Streptococcus mutans was included in the model. Therefore, it is difficult to estimate whether the contradictory results are due to the differences in ethnicity and age of the participants or to the lack of information about S. mutans level, which was not possible to analyze in our research because of some technical obstacles. Nevertheless, it is known that genetic changes in enamel genes could lead to some degree of enamel prisms disorganization and influence the enamel microhardness, that is why the strong association between tuftelin rs2337360 variant and caries incidence should be taken under consideration when concerning individual's susceptibility to caries.
While amelogenin, ameloblastin and tuftelin proteins are the main components of the tooth enamel and regulate its forming process directly, the other candidate genes included in this study play a role in the degradation of enamel proteins, i.e. matrix metalloproteinase MMP2O and kallikrein 4 KLK4. MMP2O is expressed during early stages of enamel development and, on the contrary, $K L K 4$ is expressed later during hardening of the enamel, so that genetic variants of those genes could alter protein function and disturb enamel mineralization throughout all the stages. Both genes are also implicated in hereditary defect of the enamel, i.e. amelogenesis imperfecta. ${ }^{22}$ There was no association between MMP2O variant and caries in our study, however, both SNPs for KLK4 gene were significantly associated with caries experience and indicated risk variants. In rs198969 there was 14-fold higher prevalence of the minor GG homozygote ( $p=0.0135$ ) and over 2-fold higher prevalence of the minor $G$ allele $(p=0.0049)$ in caries experienced in comparison to caries-free children, which supports this allele as a risk variant. The other KLK4 marker, rs2235091, displayed significant differences in allele distribution only. Although not significant, there was a trend for higher prevalence of the minor AA homozygote in caries-free children. Our results remain in agreement with previous study of Abbasoğlu et al., who did not observe association between $M M P 20$ variant and caries, however, they found a protective variant for $K L K 4$ gene. ${ }^{5}$ On the other hand, Wang et al. observed only borderline significant value for the role of MMP20 gene during the enamel development, similarly to the study of Tannure et al., where there were no differences in allele and genotype distribution between caries cases and controls in general studied population. ${ }^{9,22}$ Although, there were some differences in allele and genotype distribution in Caucasians only, those subjects were reported to have poor oral hygiene and health habits when compared to other participants.

Therefore, it is evident that environmental, as much as genetic factors play a role in the etiology of dental caries in children. Demographic origin also seems to be a factor of great importance, as numerous studies performed on populations of various ethnicity differ significantly in allele and genotype distribution. It is worth mentioning that genetic variants, even as subtle as single nucleotide polymorphisms in intronic region, in candidate enamel formation genes in this study, have been reported to influence other dental conditions, such as amelogenesis imperfecta or molar-incisor hypomineralization. ${ }^{23}$ It strongly supports the hypothesis that even minor alterations in gene structure could influence protein function and impact the enamel growth and mineralization and, therefore, alter individual's susceptibility to caries alongside of the environmental factors. Another possibility is that the SNPs could be in linkage to genetic variants outside the region of interest, but testing the actual influence of non-coding SNPs on protein function and 
analysis of linkage disequilibrium throughout the genome is still not a simple task. ${ }^{10,24}$ Thus, screening known genetic variants that proved to be risk variants has the potential to identify young children who may be at risk of caries and make their parents pay more attention to improve children's eating habits and oral hygiene. Moreover, it could provide genetic information about the general population, making the results more replicated and contribute to a more precise caries phenotype and better understanding of the disease. ${ }^{25}$

In conclusions one may say that single nucleotide polymorphisms in AMELX, AMBN, TUFT1, KLK4 genes may be genetic markers that contribute to dental caries occurrence in Polish children.

\section{References}

1. Wang $X$, Willing MC, Marazita ML, et al. Genetic and environmental factors associated with dental caries in children: The lowa fluoride study. Caries Res. 2012;46:177-184.

2. Duijster D, Verrips $\mathrm{GH}$, van Loveren $\mathrm{C}$. The role of family fuctioning in childhood dental caries. Community Dent Oral Epidemiol. 2014;42(3):193-205

3. Witek A, Buczkowska-Radlińska J. [Contemporary views on the role of bacteria in caries etiology - review of the literature.] Dental Forum. 2012;40(1):99-101.

4. Patir A, Seymen F, Yildirim M, et al. Enamel formation genes are associated with high caries experience in Turkish children. Caries Res. 2008;42:394-400.

5. Abbasoğlu Z, Tanboğa I, Küchler EC, et al. Early childhood caries is associated with genetic variants in enamel formation and immune response genes. Caries Res. 2015;49:70-77.

6. Olszowski T, Adler G, Janiszewska-Olszowska J, Safranow K, Kaczmarczyk M. MBL2, MASP2, AMELX, and ENAM gene polymorphisms and dental caries in Polish children. Oral Diseases. 2012;18:389-395.

7. Slayton RL, Cooper ME, Marazita ML. Tuftelin, mutans streptococci, and dental caries susceptibility. J Dent Res. 2005;84:711-714.

8. Gasse B, Grabar S, Lafont AG, et al. Common SNPs of AmelogeninX (AMELX) and dental caries susceptibility. J Dent Res. 2013;92:418-424.

9. Tannure PN, Küchler EC, Lips A, et al. Genetic variation in MMP20 contributes to higher caries experience. J Dent. 2012;40:381-386.

10. Shimizu T, Ho B, Deeley K, et al. Enamel formation genes influence enamel microhardness before and after cariogenic challenge. PLOS One. 2012;7:e45022.

11. Deeley K, Letra A, Rose EK, et al. Possible association of amelogenin to high caries experience in a Guatemalan-Mayan population. Caries Res. 2008;42:8-13.

12. Ouryouji K, Imamura Y, Fujigaki Y, et al. Analysis of mutations in the amelogenin and the enamelin genes in severe caries in Japanese pediatric patients. Pediatr Dent J. 2008;18:79-85.

13. Gerreth K, Zaorska K, Zabel M, Borysewicz-Lewicka M, Nowicki M. Association of ENAM gene single nucleotide polymorphisms with dental caries in Polish children. Clinical Oral Investigations. 2016;20(3):631-636.

14. Moradian-Oldak J. Protein mediated enamel mineralization. Front Biosci. 2012;17:1996-2023.

15. Yoshizaki K, Yamada Y. Gene evolution and functions of extracellular matrix proteins in teeth. Orthod Waves. 2013;72:1-10.

16. Gallon V, Chen L, Yang X, Moradian-Oldak J. Localization and quantitative co-localization of enamelin with amelogenin. J Struct Biol. 2013;183:239-249.

17. Simmer JP, Hu JC. Dental enamel formation and its impact on clinical dentistry. J Dent Edu. 2001;65:896-905.

18. Paine CT, Paine ML, Luo W, Okamoto CT, Lyngstadaas SP, Snead ML. A tuftelin-interacting protein (TIP39) localizes to the apical secretory pole of mouse ameloblasts. J Biol Chem. 2000;275:22284-22292.

19. McHugh ML. The odds ratio: Calculation, usage, and interpretation. Biochemia Medica. 2009;19:120-126.
20. Gabriel SB, Schaffner SF, Nguyen H, et al. The structure of haplotype blocks in the human genome. Science. 2002;21:2225-2229.

21. Hatakeyama J, Fukumoto S, Nakamura T, et al. Synergistic roles of amelogenin and ameloblastin. J Dent Res. 2009;88:318-322.

22. Wang SK, Hu Y, Simmer JP, et al. Novel KLK4 and MMP20 mutations discovered by whole-exome sequencing. J Dent Res. 2013;92: 266-271.

23. Jeremias F, Koruyucu M, Küchler EC, et al. Genes expressed in dental enamel development are associated with molar-incisor hypomineralization. Arch Oral Biol. 2013;58:1434-1442.

24. Collins A, Lonjou C, Morton NE. Genetic epidemiology of single nucleotide polymorphisms. Proc Natl Acad Sci. USA 1999;96: 15173-15177.

25. Werneck RI, Mira MT, Trevilatto PC. A critical review: An overview of genetic influence on dental caries. Oral Diseases. 2010:16:613-623. 